\title{
Pathogenesis of square bodies in ankylosing spondylitis
}

\author{
M AUFDERMAUR
}

From the Department of Pathology, Cantonal General Hospital, Lucerne, Switzerland

SUMMARY The pathogenesis of squaring of the vertebral bodies is analysed in a 25 year old patient with ankylosing spondylitis. The squaring derives from a straightening of the anteriof contour. The disease was diagnosed five years before the patient's death. The remodelling of bone that explains squaring of the vertebral bodies is described for the first time. Histologically an acute and chronic spondylitis with destruction and simultaneous rebuilding of the cortex ando the spongiosa of the vertebral bodies has been found. The development of square vertebrab bodies is shown to be based on a combination of a destructive osteitis and repair.

A characteristic squaring of the vertebral bodies in ankylosing spondylitis was first described by Rolleston. ${ }^{1}$ This author claimed that early changes in the anterior longitudinal ligament may produce a 'filling in' of the physiological concavity of the cortex of the vertebral bodies, particularly in the upper lumbar region. Romanus and Ydén showed that the initial radiological changes were as a rule in the upper and lower end of the cortex of the vertebral bodies (anterior spondylitis; the 'Romanus lesion'). ${ }^{2}$ The anterior contours of the vertebral bodies are commonly believed to straighten by dissolution of these parts. Wurm, however, proposed that the changes were due to statics and osteoporosis. ${ }^{4}$ I now describe a fully recorded case of ankylosing spondylitis that shows an osteitis with inflammatory destruction of the vertebrae and bone formation. My findings indicate that the squaring of the vertebrae in this disease is the result of an inflammatory process.

\section{Case report}

A 17 year old man complained of pain of the lower end of the spine. At the age of 20 years ascending pains extruded from the base of the spine to the thoracic region, and ankylosing spondylitis was diagnosed clinically. Movements of the lumbar and thoracic spine were restricted. Radiographs showed lateral sacroiliitis with anterior spondylitis at L4. HLA-B27 was present. Treatment consisted of physiotherapy, cross-country skiing, but no cortico-

Accepted for publication 29 December 1988.

Correspondence to Dr M Aufdermaur, Bruchmattstrasse 2a, CH6003 Lucerne, Switzerland. steroids. At 25 years of age the patient committed suicide. At necropsy the thoracic and lumbar spine were fixed with formalin. All the vertebral bodieso and the intervertebral discs were examined. They

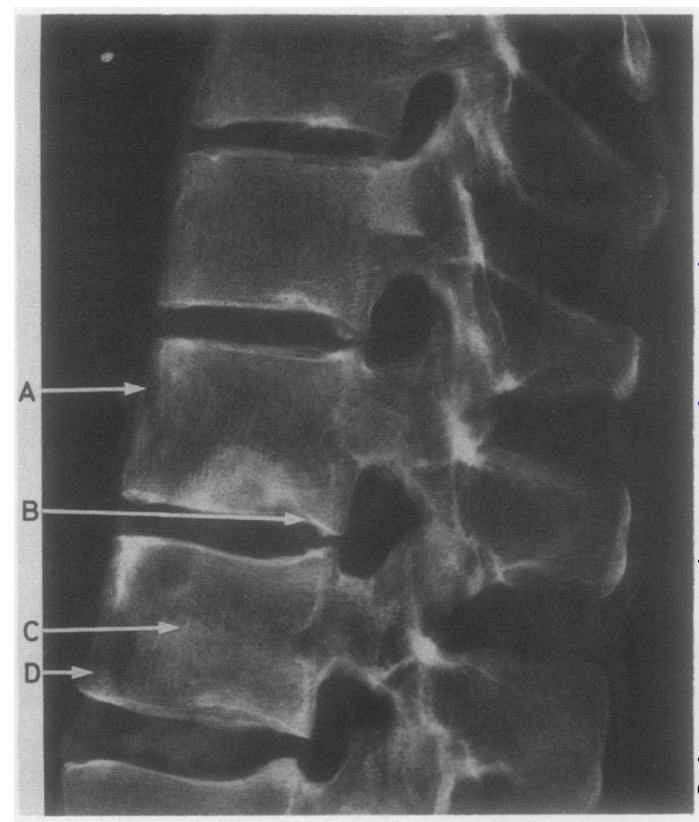

Fig. 1 Roentgenogram from T10 to L2. Erosions and simultaneous bone formation are seen at the anterior vertebral margins, resulting in squaring of the vertebral bodies. Localised radiolucencies occur with slight marginal $\vec{D}$ bone sclerosis. The intervertebral disc spaces are maintained $\frac{\text { Pे }}{\mathbb{P}}$ Disc prolapses are seen into the vertebral bodies T10-12. $A=$ Fig. 3, B=Fig. 5, C=Fig. 2, D=Fig. 4 . 


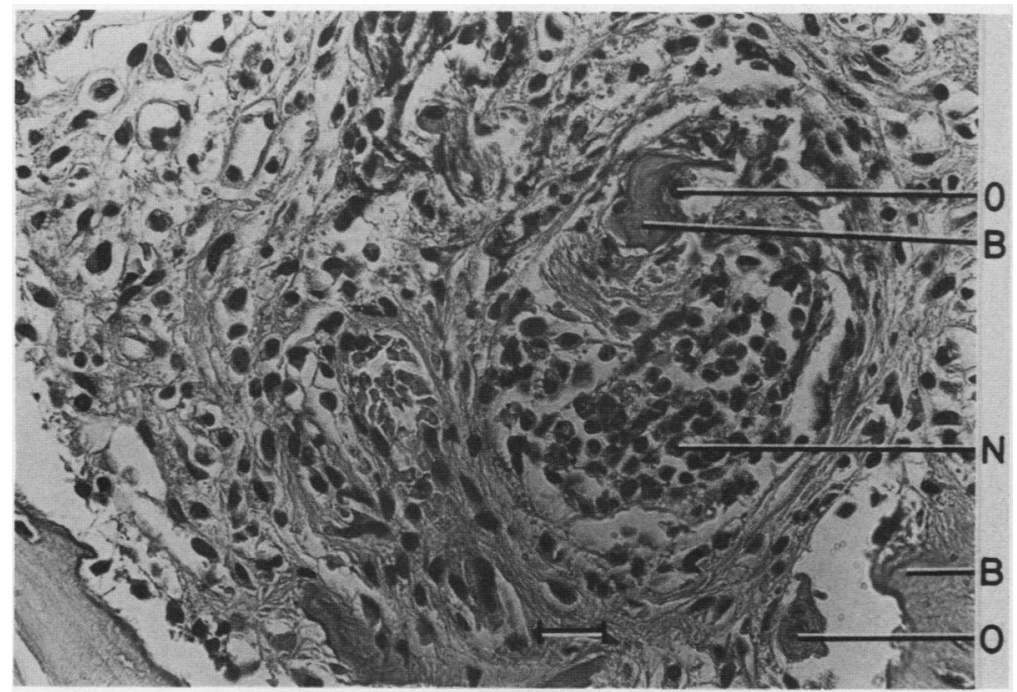

Fig. 2 Acute and chronic spondylitis and osteoclastic bone destruction. Haematoxylin and eosin. Bar $=30 \mu \mathrm{m} . \mathrm{O}=$ osteoclast; $B=$ bone fragment; $N=$ spot of polynuclear neutrophilic leucocytes.

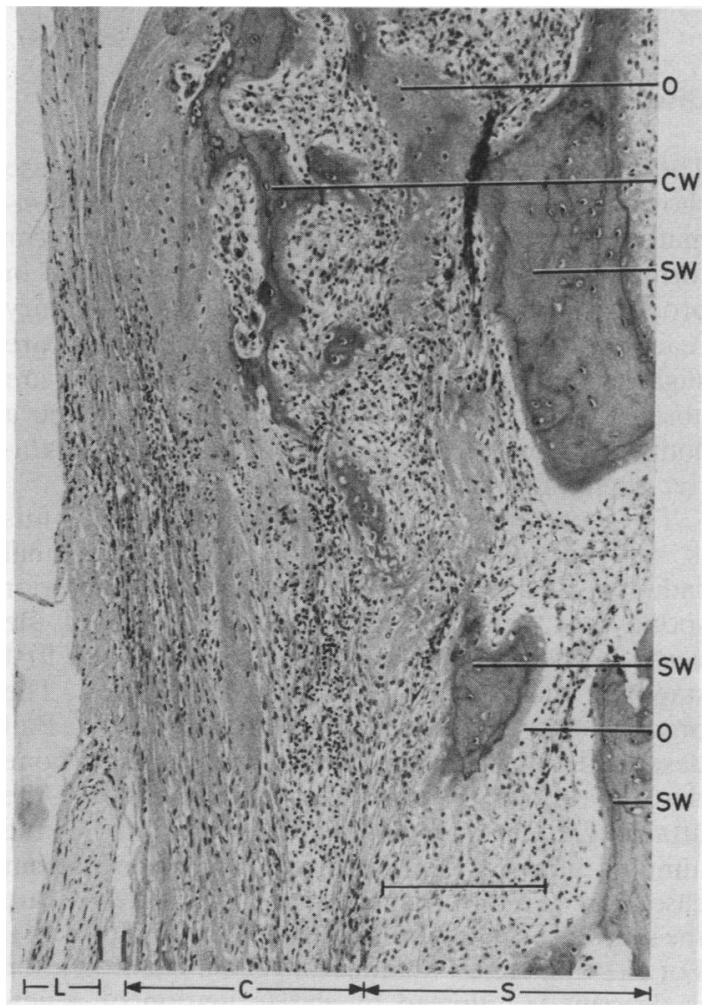

Fig. 3 Ventral cortex of the vertebral body T12 replaced by scar tissue, granulation tissue, woven bone, and osteoid. Haematoxylin and eosin. Bar $=250 \mu \mathrm{m} . O=$ osteoid; $C W=$ woven bone fragment with osteoid lining of cortex; $S W=$ woven bone fragment with osteoid lining of spongiosa; $L=$ anterior longitudinal ligament; $C=$ cortex; $S=$ spongiosa.

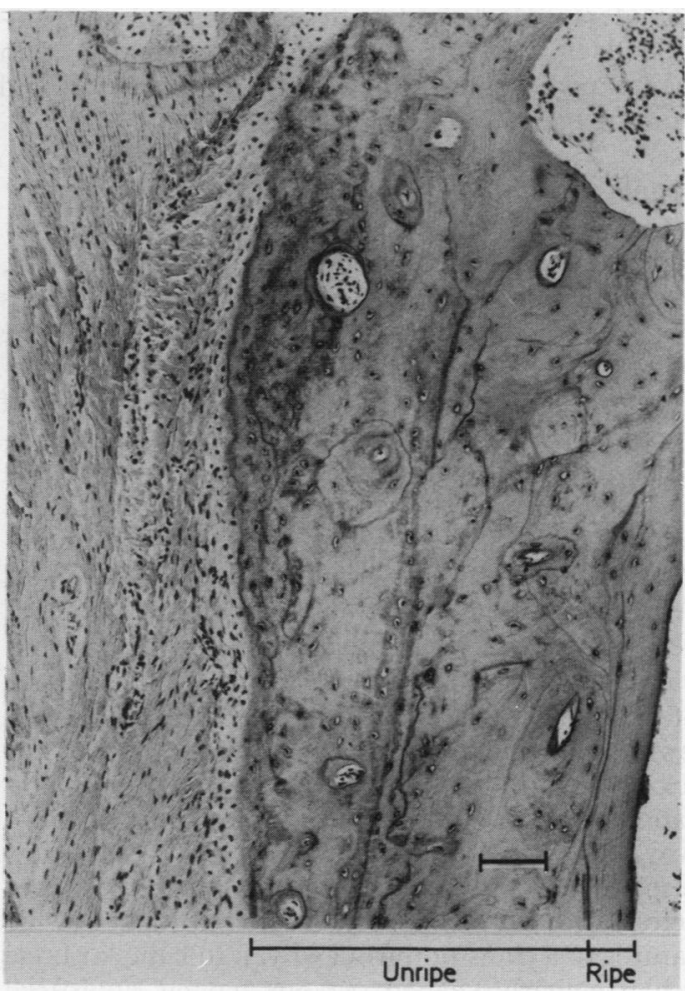

Fig. 4 New cortex of the vertebral body L5 with an unripe intermediate stage between woven and ripe lamellar bone. Haematoxylin and eosin. Bar $=90 \mu \mathrm{m}$. 


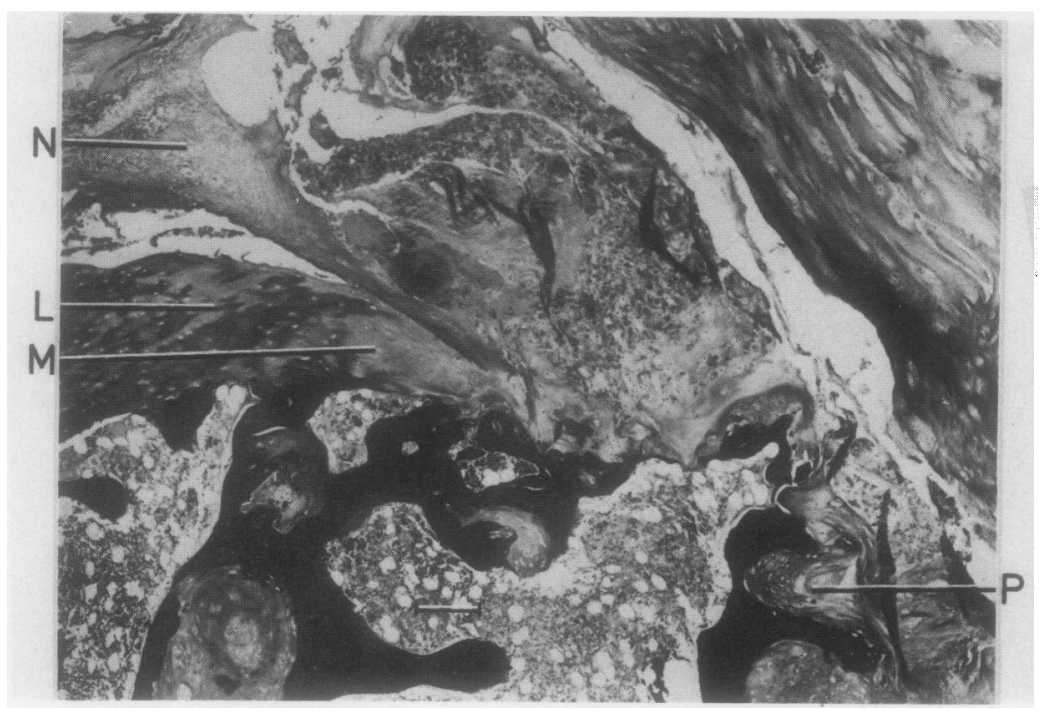

were prepared as 3-4 mm slab blocks of different diameters, decalcified with edetic acid, and embedded in paraffin. Sections were stained with haematoxylin and eosin, with the van Gieson and Gram reagents, and with alcian blue.

\section{Results}

Radiographs showed spondylitis with destruction, rebuilding, and squaring of the vertebral bodies (Fig. 1). Histologically, the bone marrow of the spongiosa contained clusters of neutrophil polymorphs (Fig. 2) together with varying amounts of granulation tissue with many lymphocytes, monocytes that display lysozyme activity, and a few plasma cells. Most of the plasma cells contained mainly IgG with a little $\operatorname{IgA}$ and IgM. No microorganisms were found. In many areas the cortex of the vertebral bodies was missing (Fig. 3). Instead, there were scars and granulation tissue with lymphocytes and monocytes as well as woven bone with osteoclastic bone reabsorption and osteoblasts with new bone formation. Haematopoietic tissue was lacking. At the sites of new bone formation inflammation was less pronounced than at some distance away. At other sites with bone formation only a few lymphocytes were present. Finally, there were sectors with a recently constructed cortex showing features of a transition from woven to lamellar bone with irregularly shaped osteons having superficial seams of osteoid. No signs of inflammation were seen in these zones (Fig. 4). The anterior longitudinal ligament was intact throughout the material.
Fig. 5 Disc prolapse T12. $N=$ nucleus pulposus. In the cartilaginous end plate the collagen $\vec{\omega}$ fibres are loosened at $L$ and missing at $M . P=$ prolapse. van Gieson. Bar $=150 \mu \mathrm{m}$.

\section{Discussion}

The histopathological findings in the present case show transitions between acute and chronic inflammatory lesions of the vertebral bodies, with scaro formation. Bone formation appears to increase in $\bar{Q}$ proportion to a decrease in the inflammatory $\overrightarrow{\vec{F}}$ reaction. In the scar tissue signs of inflammation are윽 slight; at the sites of the provisional cortex they are absent. The new bone formation appears to be af component of the osteitis and evidence of a reparative stage in the disease process.

The occurrence of osteitis in ankylosing spondylitiso is not uncommon. Romanus gave the original 3 . radiological description of the features of anterior spondylitis. ${ }^{2}$ It is confined to the margins of the vertebral bodies and can be thought of as the firsto stage in the formation of syndesmophytes. The process has been confirmed histologically. ${ }^{5-7}$ Ballo described inflammatory lesions with cortical bone destruction and reactive bone formation at the attachments of ligaments and the outer part of the $N$ annulus fibrosus ('enthesopathy'). ${ }^{6}$ In the present ${ }_{\mathrm{E}}$ case there is a different situation. The vertebrae areo the site of a primary inflammatory reaction (osteitis) For the first time inflammatory bone disintegration is described, followed by the formation of a newos cortex and spongiosa. Repair is advanced in some areas but never complete. There is a markedō variation in the thickness and extent of the cortex. $\vec{\otimes}$ The normal structure of the vertebral bodies and the $\frac{\overrightarrow{0}}{}$ concavity of their margins are absent. The primary $\frac{\varrho}{\sigma}$ osteitis therefore seems to be of decisive importance 
for the development of this structure. The role of mechanical forces in the squaring of the vertebral bodies cannot be excluded, however.

Of the four disc herniations seen in Fig. 1, in only one place is there a small inflammatory focus; it is at the ventral aspect of the prolapsed T12 disc, adjacent to the bone sclerosis. Cawley et al described histological changes closely resembling those of T12 of the present case. ${ }^{8}$ They suggested that disc herniation might be produced by osteoporosis. In the present case, however, there were no signs of osteoporosis. To my knowledge disc prolapse has not been reported to be particularly common in ankylosing spondylitis. Moreover, severely osteoporotic spines do not often show disc herniation (personal observation). It has been reported that the pathogenesis of disc herniation is based on a defect of collagen fibres in the collagenous end plates of the vertebral bodies (Fig. 5). ${ }^{5} 9$ There is, therefore, no evidence of an association with ankylosing spondylitis.

I am grateful to Dr N Fellmann and Dr H Spring, Rheumaklinik Leukerbad, for the clinical documents.

\section{References}

1 Rolleston G L. The early radiological diagnosis of ankylosing spondylitis. Br J Radiol 1947; 20: 288-93.

2 Romanus R. Pelvo-spondylitis ossificans in the male. Stockholm: Aktiebolaget Godvil, 1953.

3 Romanus R, Ydén S. Destructive and ossifying spondylitic changes in rheumatoid ankylosing spondylitis. Acta Orthop Scand 1952; 22: 88-99.

4 Wurm H. Zur pathologischen Anatomie und Pathologie der entzündlichen Wirbelsäulenversteifung (Bechterew-MarieStrümpell). Zeitschrift fur Rheumaforschung 1955; 14: 337-64.

5 Aufdermaur M. Spondylitis ankylosans. In: Doerr W, Seifert G. eds. Spezielle pathologische Anatomie. Vol 18. II. Berlin, Heidelberg: Springer, 1984: 977-1022.

6 Ball J. Enthesopathy of rheumatoid and ankylosing spondylitis. Ann Rheum Dis 1971; 30: 213-23.

7 Engfeldt B, Romanus R, Ydén S. Histological studies of pelvospondylitis ossificans (ankylosing spondylitis) correlated with clinical and radiological findings. Ann Rheum Dis 1954; 13: 219-28.

8 Cawley M I D, Chalmers T M, Kellgren J H, Ball J. Destructive lesions of vertebral bodies in ankylosing spondylitis. Ann Rheum Dis 1972; 31: 345-58.

9 Aufdermaur M, Spycher M. Pathogenesis of osteochondrosis juvenilis Scheuermann. J Orthop Res 1986; 4: 452-7. 